\title{
Study on Cultural Geography of National Traditional Sports
}

\author{
Guolong Zhou
}

Physical Education College, Jishou University, Jishou, Hunan, 416000

Keywords: cultural geography; national traditional sports

\begin{abstract}
From the perspective of regional culture, this paper discusses the characteristics of regional sports culture of national traditional sports and finds that the regional characteristics of traditional sports culture are in essence the result of the interaction between traditional sports and regional culture. This interaction has created difference in different regional sports cultures.
\end{abstract}

\section{Introduction}

Any national culture is formed and developed in a specific natural environment. Different natural environments produce different regional cultures and national cultures. The most primitive concept of culture has taught us that culture is the process of interaction between people and nature and society. There are many national traditional sports programs in China. In terms of their historical development and the main functions of their sports, they can be divided into three categories: "National Traditional Sports", such as martial arts, weightlifting, wrestling, track and field, and shooting. Projects, etc.; "Traditional and recreational sports and ethnic traditional sports", such as ball games, dance dramas, boat operas, water operas, ice and snow operas, chess operas, etc.; "health-promoting and ethnic traditional sports", such as guides, Tai Chi, and health Dance and so on. Such a huge state of the project not only has a lot to do with the rich and varied geographical and natural environment in China, but also has different social development situations. It is also closely related to the unique geographical distribution of China.

\section{Location Types of Ethnic Traditional Sports Culture}

China's core cultural area is located in the southeast of the Eurasian continent, with the desert and grasslands on the north, the high mountains and plateaus on the west and the horizon, and the east and the south facing the big sea. However, the geography in the history of Chinese culture does not only look in one direction, but it is in the four regions and the eight regions. Each region has its own innovation, and each has its own innovation and communication. It is also said that different ethnic groups and groups in different regions have formed relatively independent cultural patterns and individualities in the long and difficult historical development. Historical accumulation over a long period of time Traditional concepts, living habits, national consciousness, and cultural mentality have undoubtedly led to the inheritance of the traditional sports culture of the nation and the inheritance of traditional culture. The national sports cultural areas in China generally form the northeastern national sports culture area, the middle and lower reaches of the Yellow River national sports culture area, the middle and lower reaches of the Yangtze River national sports culture area, the northwest national sports culture area, the southwest national sports culture area, the plateau national sports culture area In the southeastern national sports cultural area, traditional ethnic sports in these areas have been formed during the Xia, Shang, and Zhou periods, and late in the Song Dynasty. 2.1 Starting from the Northeast, East and Inner Mongolia includes the Liaoning, Jilin and Heilongjiang provinces and the Inner Mongolia Autonomous Region, with an area of 1.89 million $\mathrm{km} 2$, accounting for about one-fifth of the country's total territory. The ethnic minorities in these areas mainly include the Manchu, Mongolian, Korean, Daur, Hezhe, Ewenki, and Erenchun ethnic groups. The Mongolian region spans the northern part of China and is a pastoral shepherd on the prairie. The generations are homes of plants and water; the Manchu is a long-established, diligent, and brave nation. It originally lived in the northeastern part of the "Baishan Heishui", and its origins 
can be traced back to the pre-Qin times. After the Warring States period, the "Su Shen" was called Louyi. In the Northern and Southern Dynasties and the Sui and Tang dynasties, they successively called "Veggie" and "Shu", and when they were in the Song and Liao Dynasty, they were also called "Jurchens". The Daur people live on the banks of the Nenjiang River in the northeast; the Oroqen and Hezhe people live in the Dahe River and dense forests. Their ancestors rely on fishing and hunting to support their lives. From a historical point of view, the pastoral herders and the forest residents of Northeast China were the earliest groups to contact and communicate with each other, but in comparison, forest residents lived in more settled lives, but they were similar in riding horses, archery, fishing and hunting techniques, and bravely fighting. After the occurrence, development and integration of a long historical process, unique national traditional sports have been formed in the northeastern cultural area. According to statistics, there are 103 ethnic traditional sports in the region, accounting for $10.3 \%$ of the total number of traditional ethnic sports in the country. There are about 36 representative projects, mainly including Manchu horse racing, equestrianism, riding, archery, and vaulting. Jumping camels, bucking rocks, playing tiles, picking pearls, playing with ice; Mongolians playing blues and polos; Korean water tanks walking, springboards, iron poles, turning scoops; Ewenki batons; Orochun The family's target shooting, skiing, racing sledge, Hezhe fork ball, top bar, etc. [6]. Many of these sports activities are related to hunting and hunting activities. They have many types of missiles, and they are equipped with horses. They are characterized by pulling and sliding movements and hitting small balls.

\section{Regional Diversity is the Reason for the Diversity of National Traditional Sports Culture}

National traditional sports, as the name implies, contains three meanings: one is sports, the other is national, and the third is traditional. First, the so-called sports means that such activity projects or sporting events all have the characteristics of sports. It is the purpose of human beings to exercise their own bodies in a planned and planned manner according to certain rules, so that all parts of their bodies are balanced and coordinated. . Second, the so-called nationality is that such sports activities or sports are national. This nationality is mainly manifested in its national cultural heritage. This national cultural heritage is mainly reflected in the fact that its activities or sports projects come from specific ethnic groups, reflects the ethnic cultural traditions and folk customs, and is preferred by the broad masses of the people, and has a deep national mass base in this ethnic region. Third, the so-called tradition is that this type of sports project has historical inheritance and is passed from generation to generation. Any one of these sports projects is produced in a certain historical period in the context of a specific ethnic culture, and in the process of historical development, its dross is retained, its essence is preserved, and it gradually matures and has its own ethnic group. National style and ethnic style, it is an important part of the national traditional culture. In a sense, tracing the development history of ethnic sports is like opening an encyclopedia of national culture. Indeed, national traditional sports is a representative of traditional Chinese culture. It is a vivid reproduction of production and life skills and festivals and customs of all ethnic groups over thousands of years. It contains authentic national culture. However, for a long time, due to the backward transportation in the ethnic minority areas and the low level of economic development, coupled with the concept of shackles, many traditional sports items are either self-destructing or confined to their own places. After the founding of New China, the country began to pay attention to the arrangement of traditional sports and increased the excavation and protection of traditional

culture. The traditional sports known as the "living stone" of national culture can be carried forward. According to statistics, after the founding of New China, a total of more than 1,000 traditional sports events were excavated in the country, of which more than 700 were from 55 ethnic minorities. Such as the Tibetan game yak and Ajia, the Miao shotgun, the Korean springboard, the Manchu pearl ball, the Qiang firecrackers, the Yao nationality gyro, the Blang family takraw ball and so on. In addition, different regional economic, political and cultural social factors will also lead to the adaptation of traditional sports cultures of different ethnic groups. Since cultural adaptation is a social practice activity, its adaptation must be closely linked with the level and status of social development. The overall social development that is interwoven by socio-political, economic, and 
cultural factors in different regions, due to differences in their natural geographical locations, ultimately led to the inconsistency and diversity of the national traditional sports culture's adaptation to development, and ultimately presented a variety of traditions. Sports culture landscape.

\section{Characteristics of Regional Sports Culture of Traditional Ethnic Sports}

"Regional culture is a discipline with systematic theory and belongs to the category of historical geography [2].” Regional culture has strong regional characteristics. Each regional culture presents different cultural landscapes due to various factors such as geographical environment and cultural accumulation. In recent years, with the emergence of emerging disciplines such as "cultural geography" and "historical geography" and the upsurge of cultural enthusiasm in the 21st century, the study of regional culturology in China has entered a period of rapid development and prosperity. For example, in 1998, Liaoning Education Publishing House organized and published a series of Chinese regional culture series, a full set of 24 books, which gives a more comprehensive overview of China's different regional cultural features and features. It can be said that this is the first time a more systematic display of China's regional culture. Such as "Jinyun Culture", "Central Plains Culture", "Yao Culture", "Lingnan Culture" and so on. Different ethnic production and labor methods determine the differences in physical fitness and living habits of different nationalities. Therefore, they also determine the basic characteristics of different nationalities' traditional sports culture. For example, a nation that uses hunting and production labor methods must be able to capture the survival of its prey because it must possess strong physical stamina and endurance. Therefore, many traditional sports of this nation have a lot to do with the characteristics of physical enhancement. For example, typical items include throwing, archery, climbing, long-distance running, lifting, carrying and so on. Similarly, for ethnic groups engaged in animal husbandry production and labor methods, a stable number of livestock grazing animals is a guarantee of life. Training techniques for poultry are very important. Only by mastering the techniques of better breeding and training can we increase the number of poultry survival. Therefore, there are many animal-related items in the race: horse racing, camel racing, yak cattle, yak sheep and so on. Therefore, after studying the traditional sports of northwestern ethnic groups, some scholars believe that: "The traditional sports culture of the northwestern ethnic groups has a close relationship with the natural environment, production characteristics, economic culture, lifestyle, and customs of the respective ethnic groups, from politics, economy, culture, History, religion, customs, warfare, migration, morality and other aspects showed the historical trajectory of national development and gave it a unique national cultural connotation, with distinctive nationality, history, and regionality [3].

Due to different labor methods, different national traditional sports cultures have been generated. From the above analysis, we can intuitively see that the traditional national sports culture has the following characteristics: First, the national traditional sports project system is huge and there are many projects. There are many projects whose origins and meanings are similar. This shows that the origins of traditional sports between different ethnic groups are the same. At the same time, it also shows that there are mutual contact, mutual penetration, and mutual communication between different ethnic groups. . Second, due to historical reasons, the generation of class society, with the interaction of different modes of production and labor in the national society, the possession of land and ecological resources among different ethnic groups and within the country has become more intense, leading to the occurrence of war. For this reason, training social members engaged in plundering and defending the rights to land and homeland has become an important task for the national class society. As a result, a variety of forms of physical activity derived from the production of labor were used by military training and eventually evolved into typical traditional ethnic sports. These traditional sports items with military nature are the common characteristics of the traditional ethnic sports culture in the three modes of production and labor. Third, we found that among different ethnic groups, the more ethnic minorities with complex geography and environment, there are more project activities, and the more geographically homogeneous natural 
ecological environment, the fewer their traditional sports activities. This reflects The influence of geographical environment and production methods on traditional sports. Fourth, in the long-term historical development and accumulation transition of traditional ethnic sports of many ethnic groups, traditional sports programs have various values and functions such as fitness, celebration, and entertainment.

\section{Conclusion}

China is a multi-ethnic and multi-district country. The historical background of multi-ethnic and multi-district brings about the diversity of traditional ethnic sports. The characteristics of the regional sports culture of our national traditional sports are regional, traditional and national. Traditional ethnic sports, as a product of regional activities, is the result of long-term interaction between regional sports and regional culture. Therefore, regional culture has an important influence on the formation and development of local traditional sports. Only by paying more attention to the regional characteristics of national traditional sports and exploring the process, mechanisms, and characteristics of the interaction between different traditional sports and regional culture can we study the traditional national sports culture more scientifically.

\section{Acknowledgements}

Fund Project: Hunan Provincial Philosophy and Social Science Fund (Western Project), 2015, "Cultural Geography of Original Ecological Ethnic Traditional Sports in Wulingshan Area”, Project Number: 15YBX036

2017 Hunan Provincial Department of Education Science Research Project (youth project) "Hunan Province Fitness Leisure Industry and Rural Ecotourism Integration Study", project number: 17B220)

\section{References}

[1] Cui Lequan. The History of Xiao[J]. Seeking Root, 2003, (5):86-91.

[2] Chai Jianhong. Tracing the origin of polo [J]. Sports Culture Guide, 2002, (4): 92.

[3] Li Xiumei, Zhang Lu. Analysis of the Origin of Ancient Polo in China [J]. Sports Culture Guide, 2001, (4): 52-53.

[4] Wang Junqi. Polo in Tang Dynasty poetry [J]. Sports Culture Guide, 2002, (2): 86.

[5] Lin Lin. The Origin of Polo and the Polo Movement of the Tang Dynasty [J]. Guizhou History Series, 2000, (6): 9-13. 